\title{
ANALISIS PENGARUH LATIHAN DRIBBLING CIRCUIT TERHADAP KELINCAHAN DRIBBLING SEPAK BOLA
}

\author{
Pardiman1, Bambang Yunanto ${ }^{2}$, dan Robby Putu Abdulquraesy 3 \\ ${ }^{1}$ Sekolah Tinggi Keguruan dan Ilmu Pendidikan Banten \\ ${ }^{2}$ Sekolah Tinggi Keguruan dan Ilmu Pendidikan Banten \\ ${ }^{3}$ Mahasiswa Pendidikan Kesehatan Jasmani dan Rekreasi
}

Penulis Korespondensi: pardiman727@gmail.com ${ }^{1}$, bambangyunanto01@gmail.com ${ }^{2,}$ putuqurais@gmail.com ${ }^{3}$

Artikel : Kelincahan Dribbling Sepak Bola

Penerima: Juli, 2021 Diterima: Agustus, 2021 Dipublikasikan: September, 2021

\begin{abstract}
Soccer is a very demanding game in which participants experience a variety of actions that require overall strength and prowess, speed, agility, balance, stability, flexibility, and an adequate level of endurance. Drib- bling circuit is the stages of dribbling practice in an exercise that has been systematically designed to increase the speed of dribbling football players in addition to dribbling football players for agility in playing. Agility is one component of motor freshness that is indispensable for all activities that require the speed of changing the position of the body and its parts. The purpose of this study was to determine the effect of circuit drib- bling training methods on soccer dribbling agility. The research method used is a literature study consisting of several sources such as primary sources and secondary sources. With the results There is an Effect of Dribbling Circuit Exercises before and after the implementation of soccer dribbling using the dribbling circuit training method. So it can be concluded that the dribbling circuit training method has a significant effect on soccer dribbling agility.
\end{abstract}

Keywords: Dribbling Circuit, Footbal Deibbling Agility

\begin{abstract}
ABSTRAK
Sepakbola adalah permainan yang sangat menuntut dimana peserta mengalami berbagai tindakan yang memerlukan kekuatan keseluruhan dan daya produksi, kecepatan, ketangkasan, keseimbangan, stabilitas, fleksibilitas, dan tingkat yang memadai dari ketahanan. Dribbling circuit merupakantahapan-tahapan latihan menggiring bola dalam suatu latihan yang telah dirancang secara sistematis untuk meningkatkan kecepatan dribbling pemain sepakbola selain dribbling pemain sepakbola dituntuk kelincahan dalam bermain. Kelincahan merupakan salah satu komponen kesegaran motorik yang sangat diperlukan untuk semua aktivitas yang membutuhkan kecepatan perubahan posisi tubuh dan bagian-bagianya. Tujuan penelitian ini adalah untuk mengetahui Pengaruh Metode Latihan Dribbling Circuit Terhadap kelincahan
\end{abstract}


Dribbling Sepakbola. Metode penelitian yang digunakan adalah penelitian studi literatur yang terdiri dari beberapa sumber seperti sumber primer dan sumber sekunder. Dengan hasil Terdapat Pengaruh Latihan Dribbling Circuit sebelum dan sesudah pelaksanaan dribbling sepak bola dengan menggunakan metode latihan dribbling circuit. Maka dapat disimpulkan bahwa metode Latihan dribbling circuit berpengaruh secara signifikan terhadap kelincahan dribbling sepak bola.

Kata Kunci : Dribbling Circuit, Kelincahan Dribbling Sepak Bola

\section{PENDAHULUAN}

Olahraga dapat dikatakan sebagai kebutuhan hidup untuk mencapai kesehatan jasmani dan memberi pengaruh baik terhadap perkembangan rohani, sehingga ada efisiensi kerja alat-alat tubuh, keteraturan peredaran darah, pernafasan dan pencernaan. Olahraga juga dapat membantu karakteristik masyarakat menjadi lebih baik dalam hidup, dan membentuk keselarasan jiwa dan raga sehingga mencapai keselarasan individual sosial yang mandiri. (Sururi, 2015).

Dribbling circuit adalah tahapantahapan latihan menggiring bola dalam suatu latihan yang telah dirancang secara sistematis untuk meningkatkan kecepatan dribbling pemain sepakbola. Terdapat dua rancangan program latihan circuit, yang pertama oleh O'Shea bahwa jumlah stasiun adalah 4 tempat. Total jarak pos satu sampai pos delapan adalah 30 meter dimana setiap posnya mempunyai rintangan berbeda. (Priyanto, 2015).

Kelincahan adalah kemampuan seseorang dalam merubah arah tubuhnya dengan cepat dan tepat pada waktu tertentu, sesuai dengan situasi dan kondisi yang dihadapi di lapangan tanpa kehilangan keseimbangan tubuh. Kelincahan telah didefinisikan sebagai perubahan kecepatan atau arah sebagai respon terhadap rangsangan. Misalnya, dalam kode sepakbola, kelincahan defensif melibatkan baik perubahan kecepatan, perubahan arah, atau keduanya, dan selalu sebagai reaksi terhadap penyerang dari gerakan. (Hidayat, 2015).

Setelah saya melakulan penelitian disalah satu sekolah ternyata Kelincahan dribbling sepak bola dalam peserta ekstrakurikuler siswa kelas VII-VIII SMPN 1 Kragilan Kabupaten Serang masih kurang dikarenakan kurangnya variasi latihan dribbling,Dikarenakan Metode latihan dribbling circuit yang benar dapat meningkatkan kelincahan dribbling circuit pada peserta ekstrakurikuler siswa kelas VIIVIII SMPN 1 Kragilan Kabupaten Serang.

Berdasarkan pada latar belakang masalah yang telah diuraikan di atas, penulis merumuskan masalah dalam penelitian ini yaitu "Bagaimana Analisis Potensi Latihan Dribbling Circuit Terhadap kelincahan Dribbling Sepakbo- la"? Penelitian ini bertujuan untuk menge- tahui Analisis 
Pardiman $^{1}$, Bambang Yunanto ${ }^{2}$, dan Robby Putu Abdulquraesy ${ }^{3}$. Analisis Pengaruh Latihan

Dribbling Circuit Terhadap Kelincahan Dribbling Sepak Bola

Potensı Latıhan Drıbblıng Circuıt Ierhadap kelincahan DribblingSepakbola.

\section{LANDASAN TEORI}

Sepakbola adalah permainan yang sangat menuntut dimana peserta mengalami berbagai tindakan yang memerlukan kekuatan keseluruhan dan daya produksi, kecepatan, ketangkasan, keseimbangan, stabilitas, fleksibilitas, dan tingkat yang memadai dari ketahanan. sepakbola dicirikan oleh banyak keterampilan teknis. Kemudian juga permainan sepakbola merupakan suatu cabang olahraga yang dimainkan oleh dua regu yang masing-masing regu terdiri dari 11 pemain, dan biasanya satu tim disebut juga dengan kesebelasan. (Sinan, 2015).

Sepak bola adalah masing-masing regu atau kesebelasan berusaha memasukkan bola atau mencetak gol sebanyak-banyaknya ke gawang lawannya dan mempertahankan gawangnya sendiri agar tidak kemasukan. Satu regu dinyatakan menang apabila regu tersebut memasukkan bola terbanyak ke gawang lawannya, dan apabila sama, maka permainan dinyatakan seri. Dalam permaian sepakbola masing-masing regu atau kesebelasan harus mempunyai pemain yang memiliki kemampuan fisik dan keterampilan teknik untuk bermain selama 90 menitatau lebih, agar dapat menampilkan permainan tim yang menyeluruh, terpadu serta konsisten). (No-sa, 2013).

\section{Teknik Sepakbola}

Asapun teknik yang ada dalam sepakbola adalah: a) teknik menendang bola (Passing), b) teknik menerima bola (Controlling), c) teknik menggiring bola (Dribbling), d) teknik menyundul bola (Heading), e) teknik pengenalan dan penguasaan bola dengan menggunakan insting atau perasaan (Ball feeling), f) teknik menendang bola ke arah gawang (Shooting), g) teknik gerak tipu denganbola (feinting), h) teknik penjaga gawan (goal keeping). (Andrianto, 2014).

\section{Dribbling Circuit}

Dribbling circuit adalah tahapantahapan latihan menggiring bola dalam suatu latihan yang telah dirancang secara sistematis untuk meningkatkan kecepatan dribbling pemain sepakbola. Terdapat dua rancangan program latihan circuit, yang pertama oleh O'Shea bahwa jumlahstasiun adalah 4 tempat. Total jarak pos satu sampai pos delapan adalah 30 meter dimana setiap posnya mempunyairintangan berbeda. (Priyanto, 2015)

\section{Tabel 2.1 Indikator}

Kelincahan Dribbling

\begin{tabular}{ccc} 
No & Norma & Waktu / Detik \\
\hline 1 & Sangat Baik & $\begin{array}{c}\text { Kebawah }- \\
18.00\end{array}$ \\
\cline { 3 - 3 } 2 & Baik & $19.00-21.00$ \\
\hline 3 & Sedang & $22.00-23.00$ \\
\hline 4 & Kurang & $24.00-26.00$ \\
\hline 5 & Sangat & $27.01-$ Keatas \\
& Kurang &
\end{tabular}


Pos ke satu terdapat rintangan melompati rintangan sebanyak 4 jadi siswa haris melompatinya dengan jarak 2 meter dengan kedua kaki, pos kedua terdapat 3 rintangan siswa harus berlari sprint maju mundur sesuai dengan 3 rintangan dengan jarak 1 dan 2 meter dengan menggunakan dua kaki, pada pos ke tiga terdapat 5 kun jadi siswa harus menggiring melewati kun tersebutdengan jarak 2 meter setiap kun, pada pos ke empat terdapat 4 kun kemudian siswa harus melewati maju mundur dengan jarak 1 meter. (Priyanto, 2015).

\section{Gambar 2.3 Dribbling Circuit}

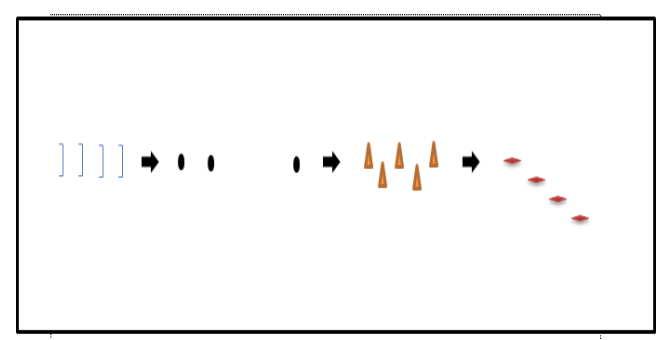

Tabel 2.2 Kelebihan dan Kekurangan Dribbling Circuit

NO

KELEBIHAN DRIBBLING

\section{CIRCUIT}

1 Pemain mudah memahami latihan kontrol, jarak dekat dengan bola, dan memfungsikan seluruh permukaan kaki.

2 Pemain juga lebih terampil dan luwes dalam menjaga bola karena dalam latihan terdapat rintangan yang berbeda setiap posnya.
3 Dengan latihan yang kontinu dan sungguh-sungguh pemain dapat mengevalusi dan memperbaiki gerakan yang salah.

$4 \quad$ Istirahat yang cukup untuk bisa melanjutkan ke repitisi berikutnya.

NO KEKURANGAN DRIBBLING CIRCUIT

1 Para pemain akan merasa sedikitjenuh dalam waktu ke depan, kreatifitas dribbling pemain kurang maksimal

2 Tingkat kelincahan rata-rata pemain terbatas.

\section{Kelincahan}

Kelincahan adalah kemampuan seseorang dalam merubah arah tubuhnya dengan cepat dan tepat pada waktu tertentu, sesuai dengan situasi dan kondisi yang dihadapi di lapangan tanpa kehilangan keseimbangan tubuh. Kelincahan telah didefinisikan sebagai perubahan kecepatan atau arah sebagai respon terhadap rangsangan. Misalnya, dalam kode sepakbola, kelincahan defensif melibatkan baik perubahan kecepatan, perubahan arah, atau keduanya, dan selalu sebagai reaksi terhadap penyerang dari gerakan. (Hidayat, 2015).

\section{METODOLOGI PENELITIAN}

Jenis penelitian ini adalah studi literatur atau penelitian kepustakaan. 
Pardiman ${ }^{1}$, Bambang Yunanto ${ }^{2}$, dan Robby Putu Abdulquraesy ${ }^{3}$. Analisis Pengaruh Latihan Dribbling Circuit Terhadap Kelincahan Dribbling Sepak Bola

Menurut Mestika Zed dalam Ahmad Yanuar Syauki penelitian kepustakaan adalah aktifitas yang pasif, statis, dan bias. yakni usaha memperoleh data dengan cara mendalami, mencermati, menelaah pengetahuan yang ada didalam kepustakaan (sumber Buku, Jurnal Internasional, Skripsi terdahulu dan Jurnal Nasional). (Ahmad Yanuar Syauki, 2020).

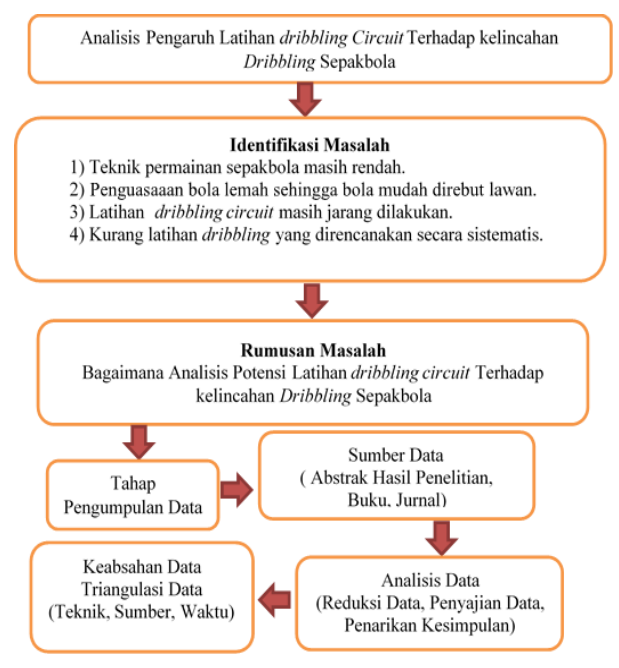

\subsection{Bagan Alur Penelitian}

\section{HASIL DAN PEMBAHASAN}

\section{Hasil}

Hasil penelitian yang didapatkan, di- peroleh 10 jurnal dan skripsi,Buku yang terkait dengan metode latihan dribbling circuit Terhadap Kelincahan Dribbling pada pemain sepakbola. Data tersebut diambil berdasarkan rangkuman intisari dari hasil penelitian yang digunakan yaitu metode latihan dribbling circuit Terhadap Kelincahan Dribbling pada pemain sepak- bola. Data tersebut diambil dan dilaporkan kembali dengan cara deskriptif kualitatif dan kuantitatif. Data hasil penemuan jurnal dan skripsi yang menggunakan metode latihan dribbling circuit Terhadap Ke-lincahan Dribbling pada pemain sepak bola.

\section{Pembahasan}

Dengan demikian dapat diketahuibahwa ada pengaruh latihan dribbling cir- cuit terhadap kelincahan dribbling sepak bola. Kondisi tersebut dikarenakan latihan dribbling circuit menggunakan metode latihan per pos dalam melakukan dribbling memiliki berbagai keuntungan yaitu memudahkan dalam hal kelincahan drib- bling sepak bola. Dalam hal ini siswa su- dah mengukur dengan baik terhadap teknik dribblingnya, baik gerakan saat melakukan dribbling, maupun gerakan kaki pada saat melakukan dribbling.

\section{PENUTUP}

\section{A. Simpulan}

Berdasarkan hasil penelitian dari sumber data primer dan sekunder,Skripsi terdahulu,Dengan demikian hasil penelitian ini dapat disimpulkan bahwa latihan dribbling circuit dapat berpengaruh positif terhadap kelincahan dribbling sepak 
bola. Hal ini terbukti pada penelitian yang telah dilakukan oleh beberapa peneliti yang terdahulu. Hasil dari penelitian yang menggunakan metode penelitian eksperimen juga meiliki hasil penelitian yang berpengaruh positif dalam kelincahan dribbling sepak bola.

Hasil yang didapatkan dari penelitian yang telah dilakukan bahwa latihan drib- bling circuit dapat berpengaruh positif terhadap kelincahan dribbling sepak bola. Pengaruh positif tersebut ditunjukan dengan meningkatnya terhadap kelincahan dribbling. Hal tersebut berdasarkan hasil penelitian terdahulu yang didasari perhitungan statistik maupun presentase.

\section{B. Saran}

Berdasarkan kesimpulan di atas, dapatdiusulkan saran yang diharapkan akan bermanfaat bagi penelitian selanjutnya:

1. Bagi Instansi Terkait

Dinas Pendidikan dan Sekolah untuk senantiasa meningkatkan Sumber Daya Manusia, sarana dan prasarana maupun perangkat dalam pembelajaran tentang konsepkonsep pembelajaran yang menarik perhatian siswa.

\section{Bagi Siswa}

Siswa hendaknya dapat lebih meningkatkan kemampuan melalui latihan dribbling circuit sehingga siswa dapat melakukan teknik dasar sepak bola dengan kemampuan yang baik untuk mendukung hasil belajarnya.

3. Bagi Peneliti Selanjutnya

a) Bagi peneliti selanjutnya yang ter- tarik untuk melakukan kajian di bi- dang yang sama dapat menambah variabel independen maupun de- penden yang memiliki kemung- kinan pengaruh kelincahan $d r i b$ - bling sepak bola.

b) Peneliti selanjutnya disarankan un- tuk menambah jumlah sumber ref- erensi sehingga penelitian dapat digeneralisasikan dengan baik.

\section{DAFTAR PUSTAKA}

Ahmad Yanuar Syauki. 2020. "Pengaruh Metode Latihan Massed Practice Terhadap Keterampilan Smash Bulutangkis". Jurnal Sportif

Andrianto, J. R. 2014. "Pengembangan Model Latihan Teknik Dasar Ball feeling Sepakbola Menggunakan Media Pembelajaran AudioVisual Pada Siswa Usia 11 Tahun Sekolah Sepakbola Sanggar Kegiatan Belajar (Ssb Skb) GudoKabupaten Jombang".Bravo's Jurnal 
Pardiman $^{1}$, Bambang Yunanto ${ }^{2}$, dan Robby Putu Abdulquraesy ${ }^{3}$. Analisis Pengaruh Latihan Dribbling Circuit Terhadap Kelincahan Dribbling Sepak Bola

Program Studi Pendidikan Jasmani dan Kesehatan STKIP PGRI Jombang 2(3): 89-97 ISSN: 2337-7674

Aprianova, F. 2016. "Metode Drill Untuk Meningkatkan Teknik Dasar Menggiring Bola (Dribbling) Dalam Permainan Sepakbola Pada Siswa Sekolah Sepakbola Putra Zodiac Kabupaten Bojonegoro Usia 1315 Tahun". Jurnal Kepelatihan Olahraga 1(1): 45-52

Apriansyah., B. 2017. "Kontribusi Motivasi, Kerjasama, Kepercayaan Diri terhadap Prestasi Atlet Sekolah Sepakbola Pati Training Center di Kabupaten Pati”. JPES 6(2): 101-107 ISSN 2252-684X

Ghani., M. A 2017. "Pengaruh Latihan Resistance Band dan Power Tungkai Terhadap Peningkatan Hasil Tendangan Lambung Dalam Sepak Bola Pada Atlet SSB Sriwijaya Asah Soccer U-15 Palembang" JPES 1-7: ISSN 2252$648 \mathrm{X}$

Hidayat., W. 2015. "Evaluasi Program Pembinaan Prestasi Sepakbola Klub Persibas Banyumas". Journal Of Phisical Education and Sport 4(2): 10-15 ISSN 2252-6528

Nosa., A. S. 2013. "Survei Tingkat Kebugaran Jasmani Pada Pemain Persatuan Sepakbola Indonesia Lumajang". Jurnal Prestasi Olahraga $3(1): 1-8$

Pranatha., C. Y. 2016. "Pengaruh Pelatihan Dribbling Slalom dan Dribbling Bebas Terhadap Keterampilan Menggiring Bola Pada Peserta Ekstrakulikuler SepakBola Smp Negeri 2 Sawan". JurnalKeolahragaan 2(1): 1-7
Pratama, M. (2020). Metode Circuit Training Berpengaruh Terhadap Kemampuan

Dribbling Sepakbola.

Razif, M. (2020). Pengaruh Latihan Dribbling Circuit Dan Kelincahan Terhadap Kemampuan Dribbling SSB Putra Wijaya.

Santosa., N 2014. "Tingkat Keterampilan Passing-Stoping Dalam Permainan Sepakbola Pada Mahasiswa Pjkr B

Angkatan 2013". Jurnal Pendidikan Jasmani Indonesia 10(2):40-48

Setio Aji. 2018. "Pengaruh metode latihan dribbling circuit Terhadap Ke- lincahan Dribbling pada pemain sepakbola KU 14-16 SSB Tunas Muda di Kota Bengkulu".

Silaen, A. H., 2017."Pengaruh Metode Latihan Hollow Sprint acceleration Sprint dan Kelincahan Terhadap Daya Tahan Anaerobic Pada Pemain Sepakbola Ku 14-16ssb Tunas Muda Di Kota Bengkulu". Tesis. Semarang: Universitas Negeri Semarang.

Wasis Adi Priyanto. 2015. "Pengaruh Latihan Dribbling Sirkuit dan Metode Bermain Terhadap Kecepatan Dribbling Bola Pada Pemain Sekolah Sepakbola Pelangi” 
